\title{
Compliance with Statutory Tobacco Guidelines in and around Schools in Mangaluru, India: An Observational Study
}

\author{
${ }^{1}$ Ravi Priyanka, ${ }^{2}$ Ashwini Rao, ${ }^{3} \mathrm{G}$ Rajesh, ${ }^{4}$ Shenoy Ramya, ${ }^{5}$ Pai BH Mithun
}

\begin{abstract}
Context: Tobacco is the foremost cause of preventable death and disease in the world today, and India is the second largest consumer of tobacco products in the world. The Cigarettes and Other Tobacco Products Act (COTPA) promulgated in 2003 by the Government of India, not only mandates ban on the sale of tobacco within a 100-yard radius around schools, but also provides guidelines for tobacco-free schools.
\end{abstract}

Aim: To determine if the provisions of the COTPA are being complied with, in Mangaluru, India.

Materials and methods: A cross-sectional study was conducted among 30 randomly selected schools in Mangaluru, India. Information was collected regarding sale of tobacco at vendor locations within 100-yard radius of these schools. An interview schedule was administered to the representative of the school, pertaining to the guidelines for tobacco-free schools.

Statistical analysis used: The data were coded and analyzed using the Statistical Package for Social Sciences (SPSS) version 11.5. The level of statistical significance was kept at $\mathrm{p}<0.05$.

Results: There were 48 shops located within 100-yard radius of the schools, out of which $46(95.8 \%)$ sold single cigarettes but only one shop displayed surrogate advertisement. Among the 30 schools surveyed, only $3(10 \%)$ displayed signages prohibiting smoking. Although the guidelines for tobacco-free schools explicitly state that all schools must have a copy of the COTPA, only 3 (10.0\%) schools maintained a copy.

Conclusion: This study showed that there was a widespread violation of Section 6 of the COTPA 2003 in Mangaluru, India.

Keywords: Health policy, School health, Smoking, Tobacco.

How to cite this article: Priyanka R, Rao A, Rajesh G, Ramya S, Mithun PBH. Compliance with Statutory Tobacco Guidelines in and around Schools in Mangaluru, India: An Observational Study. World J Dent 2017;8(1):10-13.

Source of support: Nil

Conflict of interest: None

${ }^{1}$ Postgraduate Student, ${ }^{2}$ Professor, ${ }^{3}$ Professor and Head ${ }^{4,5}$ Associate Professor

${ }^{1-5}$ Department of Public Health Dentistry, Manipal College of Dental Sciences, Manipal University, Mangaluru, Karnataka, India

Corresponding Author: Ashwini Rao, Professor, Department of Public Health Dentistry, Manipal College of Dental Sciences Manipal University, Mangaluru, Karnataka, India, Phone: +919845337155, e-mail: Ashwini.rao@manipal.edu

\section{INTRODUCTION}

Tobacco is the foremost cause of preventable death and disease in the world today, and India is the second largest consumer of tobacco products in the world. Tobacco use is claiming the lives of nearly six million people a year worldwide, including more than 600,000 nonsmokers who die from exposure to second-hand smoke. The death toll from tobacco is expected to increase to eight million a year by $2030 .^{1}$

The Global Youth Tobacco Survey (GYTS) ${ }^{2}$ indicates that $14.6 \%$ children in the age group of 13 to 15 years and $34.6 \%$ of Indians aged 15 years and above use tobacco in some form or the other. Every year more than 8 lakh people die due to tobacco-related diseases. ${ }^{2}$

It has also been reported that more than $39 \%$ of tobacco users initiated the tobacco habit before the age of 17 years when they were far too young to either resist peer pressure or understand the risks of tobacco use. ${ }^{3}$

The Cigarettes and Other Tobacco Products Act (COTPA) (prohibition of advertisement and regulation of trade and commerce, production, supply and distribution) was enacted by the Government of India in 2003. The Act prohibits advertisement, regulates trade and commerce as well as production, supply, and distribution of cigarettes and other tobacco products. According to the Section 6 of the COTPA 2003, no person can sell or permit sale of cigarette or any other tobacco product to anyone under 18 years of age and in an area within a radius of 100-yard of any school. ${ }^{4}$

Although any person who breaks the rules of Section 6 the COPTA shall be guilty of offence and punishable with fine, sale of tobacco products are reported to be rampant around educational institutions at least in some parts of India. ${ }^{5}$

The Ministry of Health and Family Welfare, Government of India, has issued guidelines for tobacco-free schools/educational institutions. ${ }^{6}$ Search of available literature, however, found very few studies regarding compliance with these guidelines. The absolute lack of evidence emanating from this part of India led to the conceptualization of this study, with the aim of determining if there is compliance with statutory tobacco guidelines in and around schools in Mangaluru, India. 


\section{MATERIALS AND METHODS}

The study was a cross-sectional type of an observational study, conducted among schools in Mangaluru City. The list of all schools was obtained from the Block Education Officer. Cluster random sampling was done by dividing the area into four zones, i.e., North, South, East and West zones using the Mangaluru city map. Equal number of schools was randomly selected from each cluster to get a sample size of 30 . Tobacco vendors within 100-yard radius of these schools were also identified. Ethical clearance was obtained from the Institutional Ethics Committee (Ref no. 15034 dated 7 March 2015).

An interview schedule was administered by the investigator to the head/representative of school and consisted of 12 items pertaining to the guidelines for tobacco-free schools/educational institutions issued by the Ministry of Health and Family Welfare, Government of India. The participants were given a dichotomous choice of "yes" or "no" for each item.

At vendor locations where tobacco was sold, information was collected regarding location, type of vendor, shop type, type of tobacco sold, single tobacco sale, type of advertisement, brand name, health warnings on advertisements, number of advertisements, and surrogate advertisement.

\section{Data Analysis}

The data were coded and analyzed using the Statistical Package for Social Sciences (SPSS) version 11.5. The level of statistical significance was kept at $\mathrm{p}<0.05$. Descriptive statistics have been presented.

\section{RESULTS}

This study showed that a total of 57 shops were present within 100-yard radius of the participating schools, out of which tobacco was sold in 48 (84.2\%) shops. Each school had at least one tobacco vending shop within 100-yard radius of the school. Surprisingly, 15 shops were exclusively pan shops selling smoked and/or smokeless forms of tobacco (Table 1).

Table 1: Distribution of shops within 100 yards of participating schools in Mangaluru

\begin{tabular}{llll}
\hline Sl. no. & Type of vendor & $\begin{array}{l}\text { No. of shops } \\
\text { selling tobacco }\end{array}$ & $\begin{array}{l}\text { No. of shops not } \\
\text { selling tobacco }\end{array}$ \\
\hline 1 & Pan shop & $15(31.3)$ & 0 \\
2 & Tea stall & $4(8.3)$ & $1(11.1)$ \\
3 & Grocery store & $29(60.4)$ & $3(33.3)$ \\
4 & Bakery & 0 & $4(44.4)$ \\
5 & Supermarket & 0 & $1(11.1)$ \\
\hline & Total & $48(84.2)$ & $9(15.8)$ \\
\hline
\end{tabular}

Figures in parenthesis represent percentages
The different types of tobacco products available in the shops were cigarette, beedi, ghutka, and snuff. Only cigarette was sold in 4 shops, cigarette and beedi sale was seen in 7 shops, cigarette and ghutka were sold in 16 shops, cigarette, beedi, and ghutka together were sold in 3 shops, and all the four products were sold in 18 shops. Out of them, $46(95.8 \%)$ shops even sold single cigarettes but only $1(2.0 \%)$ shop displayed surrogate advertisement (Table 2).

When we administered the interview schedule to the school representative, to find out the compliance with "guidelines for tobacco-free schools" of participating schools in Mangaluru City, we found that among the 30 schools surveyed, although signages with respect to "Tobacco-free School" or "Tobacco-free Institution" were displayed by 15 (50\%) schools, only 3 schools (10\%) displayed the sign board "No smoking area - Smoking here is an offence" in their premises (Table 3).

One school even reported that they did not stop students/teachers/other staff members from smoking/ chewing of tobacco within the school premises. Only 4 (13.3\%) schools had a "Tobacco Control Committee" in their school, whereas $26(86.7 \%)$ schools reported that tobacco control activities were integrated with school health programs. About $63 \%$ of the schools reported that they conduct poster themes on tobacco control (Table 3).

Only $2(6.7 \%)$ schools reported to have consulted the State Nodal Officer for Tobacco Control in the State Health Directorate, and although the guidelines for tobacco-free schools explicitly state that all schools must have a copy of the COTPA, only 3 (10.0\%) schools maintained a copy (Table 3).

\section{DISCUSSION}

This study is the first of its kind conducted to report the compliance with statutory tobacco guidelines in and around schools in Mangaluru, India. Tobacco vendors within a 100-yard radius of the participating schools were identified and information was collected on sale and advertisement of tobacco. This study also assessed if the schools were following the guidelines for

Table 2: Characteristics of tobacco sale within 100 yards of participating schools in Mangaluru

\begin{tabular}{lll}
\hline SI. no. & Item & $n(\%)$ \\
\hline $\begin{array}{l}\text { Type of } \\
\text { tobacco sold }\end{array}$ & Only cigarette & $4(8.3)$ \\
& Only cigarette and beedi & $7(14.5)$ \\
& Only cigarette and ghutka & $16(33.3)$ \\
& Cigarette, beedi, and ghutka & $3(6.2)$ \\
& Cigarette, beedi, ghutka, and snuff & $18(37.5)$ \\
3 & Single tobacco sale & $46(95.8)$ \\
\hline
\end{tabular}

Figures in parenthesis represent percentages 
Table 3: Compliance with "guidelines for tobacco-free schools" of participating schools in Mangaluru

\begin{tabular}{cll}
\hline Sl. & Particulars & No. of compliant \\
no. & schools (\%)
\end{tabular}

Figures in parenthesis represent percentages computed vertically for each group

tobacco-free schools issued by the Ministry of Health and Family Welfare, Government of India.

Our study showed that a total of 48 shops selling tobacco were present within 100-yard radius of the 30 participating schools and $100 \%$ of the schools had at least one tobacco vending shop within 100-yard radius of the school. Elf et $\mathrm{al}^{5}$ conducted a similar study in Ahmedabad and reported that $87 \%$ schools had tobacco sales within 100-yard of their entrance. Studies ${ }^{1,7}$ have shown that in India, there is easy accessibility of residences and schools to tobacco outlets. However, a study conducted by Kirchner et $\mathrm{al}^{8}$ in Washington, DC, found that illicit tobacco sales to minors were occurring at very low rates.

McCarthy et $\mathrm{al}^{9}$ and Shortt et al ${ }^{10}$ found a significant association between density of tobacco retail outlets in the neighborhoods and increased odds of smoking habit among adolescents. Similar findings were reported by Cantrell et $\mathrm{al}^{11}$ who found that as the density of outlets within walking distance of the home increased, tobacco cessation activity was reduced among smokers.

Elf et $\mathrm{al}^{5}$ in their study conducted in Ahmedabad, India, found $70 \%$ of the shops around schools selling cigarettes singles. However, in the present study, out of the 48 shops vending tobacco, 46 (95.8\%) shops sold single cigarettes and 15 were exclusively pan shops selling smoked and/or smokeless forms of tobacco. In spite of the ban on tobacco advertising, one shop in our study displayed surrogate advertisement, within 100-yard radius of the school. Patel et $\mathrm{al}^{12}$ reported that tobacco promotion activities like advertising, sale of tobacco in singles in school location were found to be associated with adolescent tobacco initiation in Gujarat.

Kaur et $\mathrm{al}^{13}$ conducted a survey in Chennai and found that only $0.7 \%$ schools displayed the signage of ban on sale of tobacco products and $2.8 \%$ schools had the signage displaying prohibition of smoking. In the present study, the signage of ban on sale of tobacco products was displayed in $50 \%$ of the schools, whereas signage displaying prohibition of smoking was displayed only in $10 \%$ of the schools. In the current study, around $87 \%$ of schools had tobacco control activities integrated with School Health Programs. Studies ${ }^{1,14}$ have shown that comprehensive tobacco prevention programs might help reduce youth smoking whereas scarcity of relevant teaching materials and lack of training among school personnel might undermine the efforts in preventing or reducing adolescent tobacco use.

\section{CONCLUSION}

In spite of the inherent limitations of any questionnaire study, this study showed that although the compliance of schools with respect to guidelines for tobacco-free schools/educational institutions issued by the Ministry of Health and Family Welfare, Government of India is good compared to other studies, there is a need to target for $100 \%$ compliance with these guidelines. However, with respect to the sale of tobacco around 100 yards radius of schools, we have found that there was widespread violation of Section 6 of the COPTA 2003 in Mangaluru, India. In spite of the presence of legislation to prevent tobacco exposure to those below 18 years of age, there is lack of information regarding its implementation. There is also a lack of total compliance of schools with respect to guidelines for tobacco-free schools/educational institutions issued by the Ministry of Health and Family Welfare, Government of India.

It is therefore important for school authorities to be updated about the guidelines for tobacco-free schools. School authorities have a role to play in not only identifying tobacco retailers near schools but they also have to see that action is taken on these vendors by the law enforcing personnel. Proactive participation of both the school system as well as the legal system would definitely help in effective enforcement of Section 6 of the COTPA, thus preventing tobacco exposure among school children and safe guarding the health of our future generation. Bringing about awareness among the concerned authorities as well as enforcement of existing laws is the need of the hour. 


\section{REFERENCES}

1. Sinha DN, Palipudi KM, Rolle I, Asma S, Rinchen S. Tobacco use among youth and adults in member countries of SouthEast Asia region: review of findings from surveys under the global tobacco surveillance system. Indian J Public Health 2011 Jul-Sep;55(3):169-176.

2. Panda B, Rout A, PatiS, Chauhan AS, Tripathy A, Shrivastava R, Bassi A. Tobacco control law enforcement and compliance in Odisha, India - implications for tobacco control policy and practice. Asian Pac J Cancer Prev 2012;13(9):4631-4637.

3. Goel S, Kumar R, Lal P, Tripathi J, Singh RJ, Rathinam A, Christian A. How compliant are tobacco vendors to India's tobacco control legislation on ban of advertisements at point of sale? A three jurisdictions review. Asian Pac J Cancer Prev 2014;15(24):10637-10642.

4. The Cigarette and other Tobacco Product Act, 2003 [Internet] [last accessed 7 Feb 2015]. Available from: http://mohfw.nic. in/WriteReadData/1892s/file9-61090433.pdf.

5. Elf JL, Modi B, Stillman F, Dave P, Apelberg B. Tobacco sales and marketing within 100 yards of schools in Ahmedabad City, India. J Public Health 2013 May;127(5):442-448.

6. Guidelines for Tobacco-free Schools/Educational Institutions [Internet] [last accessed 7 Feb 2015]. Available from: http://www.mohfw.nic.in/WriteReadData/1892s/file3081207361.pdf.

7. Schensul JJ, Nair SS, Bilgi S, Cromley E, Kadam V, Mello SD, Donta B. Availability, accessibility and promotion of smokeless tobacco in a low-income area of Mumbai. Tob Control 2013 Sep;22(5):324-330.
8. Kirchner TR, Villanti AC, Cantrell J, Anesetti-Rothermel A, Ganz O, Conway KP, Vallone DM, Abrams DB. Tobacco retail outlet advertising practices and proximity to schools, parks and public housing affect Synar underage sales violations in Washington, DC. Tob Control. doi:10.1136/tobaccocontrol2013-051239.

9. McCarthy WJ, Mistry R, Lu Y, Patel M, Zheng H, Dietsch B. Density of tobacco retailers near schools: effects on tobacco use among students. Am J Public Health 2009 Nov;99(11): 2006-2013.

10. Shortt NK, Tisch C, Pearce J, Richardson EA, Mitchell R. The density of tobacco retailers in home and school environments and relationship with adolescent smoking behaviours in Scotland. Tob Control 2016 Jan;25(1):75-82.

11. Cantrell J, Anesetti-Rothermel A, Pearson JL, Xiao H, Vallone D, Kirchner TR. The impact of the tobacco retail outlet environment on adult cessation and differences by neighborhood poverty. Addiction 2015 Jan;110(1):152-161.

12. Patel D, Kassim S, Croucher R. Tobacco promotion and availability in school neighborhoods in India: a cross-sectional study of their impact on adolescent tobacco use. Asian Pac J Cancer Prev 2012;13(8):4173-4176.

13. Kaur P, Thomas DR, Govindasamy E, Murhekar MV. Monitoring smoke-free laws in restaurants and educational institutions in Chennai, India. Natl Med J India 2014 Mar-Apr;27(2):76-78.

14. Agaku IT, Obadan EM, Odukoya OO, Olufajo O. Tobacco-free schools as a core component of youth tobacco prevention programs: a secondary analysis of data from 43 countries. Eur J Public Health 2015 Apr;25(2):210-215. 